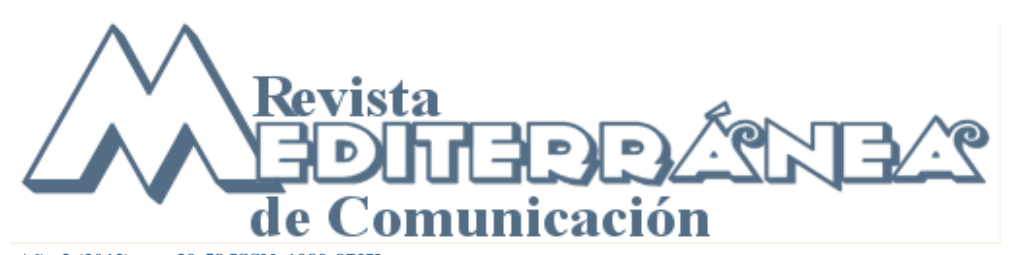

Año 3 (2012), pp. 39-58 ISSN 1989-872X

Fecha de recepción: 21/12/2011; Fecha de publicación: 05/02/2012

\title{
Juventud y discurso mediático. El tratamiento periodístico de las personas jóvenes en los medios de Cataluña.
}

\section{Youth and media discourse. The journalistic treatment of young people in Catalan's media.}

\author{
Dr. Marcel Mauri de los Rios \\ Profesor de Deontología Periodística \\ Universitat Pompeu Fabra. Departamento de Comunicación (UPF)-España \\ marcel.mauri@upf.edu \\ Dra. Mònica Figueras Maz \\ Profesora de Deontología Periodística \\ Universitat Pompeu Fabra. Departamento de Comunicación (UPF)-España \\ monica.figueras@upf.edu
}

\section{Resumen}

En este artículo se presentan parte de los resultados de una investigación más amplia: el análisis de la presencia de los jóvenes en los medios informativos de más audiencia en Cataluña y cómo estos medios elaboran el discurso sobre este colectivo atendiendo a las fuentes periodísticas usadas, las formas de titular o la propia actitud del narrador a partir de una metodología que aplica técnicas cualitativas y cuantitativas. El artículo contempla también la reflexión que existe sobre el tratamiento periodístico de las personas jóvenes entre los propios periodistas, por un lado, y los agentes de juventud, por otro a través de las respuestas obtenidas con técnicas cualitativas.

\section{Abstract}

This article presents the results of further investigation: the analysis of the presence of young people in the highest rated media in Catalonia and how this media made their discourse about this collective on the basis of journalistic sources used, the analysis of the headlines, and the narrator's attitude from a methodology that applies qualitative and quantitative techniques. The article also includes the journalists thinking about press coverage of young people, on the one hand, and professionals working with young people, on the other, through the answers obtained with qualitative techniques.

Palabras claves

Ética; deontología; periodismo; prensa; radio; televisión; España. 


\section{Key Words}

Ethics; deontolog; journalism; press; radio; television.

Sumario: 1.Introducción. 2. Marco teórico. 2.1 La juventud en los medios de comunicación. 2.2 Principios de actuación periodística: justicia y responsabilidad. 2.3 Las rutinas de producción periodística. 3. Objetivos y metodología. 4. Resultados. 4.1 La presencia y perfil de las personas jóvenes en los medios. 4.2 Las noticias sobre jóvenes en titulares y portadas. 4.3 Los géneros informativos. 4.4 Las fuentes informativas. 4.5 La actitud del narrador. 4.5.1 Joven individual o juventud colectiva. 4.5.2 Tema de la noticia. 5. Discusión. 6. Bibliografía. 7. Notas.

Summary: 1. Introduction. 2. Theoretical Framework. 2.1 Youth in the media. 2.2 Journalistic Principles: fairness and responsibility. 2.3 Journalistic routines. 3 . Objectives and Methodology. 4. Results. 4.1 Presence and profile of young people in the media. 4.2 Young people in News headlines and front page. 4.3 Information genres. $\quad 4.4$ Information sources. 4.5 The attitude of the narrator. 4.5.1 Youth: individually or collectively. 4.5.2 Topic of the news. 5. Discussion. 6. Bibliography. 7. Notes.

\section{Introducción}

Los medios de comunicación tienen la función social primordial en una sociedad democrática de garantizar el derecho a la información de la ciudadanía. Sin embargo, el ejercicio de este derecho colectivo a menudo colisiona con otros intereses ya sean individuales o de grupo. Las personas jóvenes pueden ser consideradas como uno de los grupos llamados "socialmente desfavorecidos" atendiendo a las desigualdades de acceso y tratamiento estereotipado en los medios de comunicación. La responsabilidad en la creación de estereotipos es sin duda compartida por muchos agentes pero el poder socializador de la prensa, la radio, la televisión e internet es evidente.

El análisis de los estereotipos se ha fijado en la publicidad y la ficción, en cambio, la información, y el periodismo en general, se han considerado "reflejo" de la realidad y se han investigado menos. El objetivo del presente estudio es analizar cuál es actualmente la imagen de las personas jóvenes que ofrecen los medios de comunicación en Cataluña. El estudio es previo a las movilizaciones del 15M (transversales en edad pero eminentemente juveniles) pero precisamente da respuesta a muchas de las demandas de este colectivo en cuanto a la imagen que de las personas jóvenes se proyecta en los medios de comunicación.

El estudio, impulsado y financiado por la Secretaría de Juventud de la Generalitat de Cataluña, culminó con una propuesta de diferentes mecanismos que puedan ayudar a un tratamiento adecuado de las personas jóvenes y con la redacción de un decálogo de recomendaciones dirigido a profesionales de la comunicación ${ }^{1}$.

En este artículo se presentan los resultados de una parte específica de la investigación: el análisis de la presencia de los jóvenes en los medios informativos de más audiencia en Cataluña y cómo estos medios elaboran el discurso sobre este colectivo atendiendo a las fuentes periodísticas usadas, las formas de titular o la propia actitud del narrador, entre otros aspectos. Por otra parte, se presenta la reflexión que existe sobre el tratamiento periodístico 


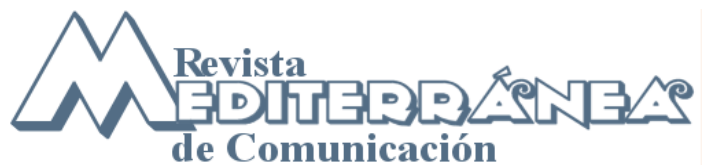

ISSN 1989-872X - Año3 (2012), pp. 39-58

de las personas jóvenes entre los propios periodistas, por un lado, y los agentes de juventud, por otro,

\section{Marco teórico}

\subsection{La juventud en los medios de comunicación}

La juventud no es una categoría homogénea y, en este sentido, es difícil definirla. Hay perspectivas que ponen el acento en el carácter transitorio y previo a la edad adulta y hay otros en la misma experiencia de ser joven. La visión tradicional de la juventud como un momento de tránsito para llegar a lo deseable, la vida adulta, ha quedado obsoleta y la juventud ha ganado entidad propia. Es casi más relevante "estar en la juventud" que "pasar por ella" (Martín Serrano y Velarde $\left.{ }^{2}, 2001\right)$. La juventud o adolescencia no se definen sólo por cuestiones biológicas sino también culturales. Las personas jóvenes son el reflejo de la sociedad donde viven; así, para aproximarse a ellas, hay que analizar el contexto cultural donde están inmersos. De ahí la importancia de analizar los medios de comunicación.

Si es difícil encontrar consenso en una definición, más aún en fijar unos límites de edad. Estos tampoco tienen que ver sólo con rasgos biológicos (Erikson ${ }^{3}$, 1968) sino que dependen de cada momento histórico-social. Existen unos límites legales (la mayoría de edad), institucionales (los fijados por la administración) o sociales (matrimonio, paternidadmaternidad...), pero en ningún caso generalizables. En España, el período se está alargando considerablemente dada la tardía incorporación a una situación más o menos estable en el mercado laboral y, por tanto, el retraso en la emancipación. Ahora bien, el alargamiento del período se da también por abajo. La ley educativa que obliga a los 12 años a dejar la escuela para ir al instituto ha acelerado el proceso de incorporación a estilos de vida, consumo y ocio juveniles (Casal y otros ${ }^{4}, 2004$ ).

Según el antropólogo Carles Feixa ${ }^{5}$ (1993), para que exista la juventud deben existir, por un lado, las condiciones sociales, es decir, las normas, los comportamientos y las instituciones que distinguen a las personas jóvenes de otros grupos de edad y, por el por otro, una serie de imágenes culturales, es decir, valores, atributos y ritos asociados específicamente a ellas. Y, en este sentido, el rol de los medios de comunicación es clave. Bandura ${ }^{6}$ (1980) introdujo el concepto de "modelaje" en el sentido de la presencia de estereotipos como fuente de aprendizaje para los espectadores que acaban extrapolando los modelos a su realidad. El periodista Walter Lippman ${ }^{7}$ ya en el año 1922 se refería a ciertas imágenes culturalmente determinadas que se mezclaban con las facultades cognitivas del individuo y sus percepciones respecto al mundo que le rodea. Ya hace tiempo que son conocidos los efectos que una estigmatización puede tener en el propio colectivo afectado. Es lo que se conoce como la "profecía de autocumplimiento" (Merton $\left.{ }^{8}, 1970\right)$; lo que de entrada es un simple estereotipo, a fuerza de repetirse, puede acabar haciéndose realidad.

La juventud en los medios de comunicación tiene asociadas dos grandes imágenes contrapuestas: la idealizada, a menudo en la publicidad (joven como valor, ya sea desde el punto de vista estético, de salud, o de estilo de vida) o la estigmatizada, a menudo en la ficción y la información (personas egoístas, hedonistas, violentas, sin valores...). La cobertura mediática de los jóvenes bascula entre dos posiciones completamente opuestas: por un lado son representados como criminales y por otro como víctimas (Falchikov ${ }^{9}, 1986$; Porteous y Colston $\left.{ }^{10}, 1980\right)$. Como explica Devlin ${ }^{11}$ (2005), la representación que los medios han hecho normalmente de los jóvenes es predecible, incluso se puede decir que este 
tratamiento mediático de la juventud es tan antiguo como la prensa misma (Pearson ${ }^{12}$, 1983). Las opiniones adultocráticas sobre la juventud se transmiten a través de los medios de comunicación, entre otras instituciones, y generan una visión determinada, normalmente sesgada sobre el colectivo. En este punto coinciden muchos estudios realizados en España a lo largo de las últimas décadas (Baca ${ }^{13}$, 1998; Giró ${ }^{14}$, 2003; Alcoceba y Cadilla ${ }^{15}, 2010$ y 2007; Consell de l'Audiovisual de Catalunya ${ }^{16}, 2010$; Luzón y otros ${ }^{17}, 2009$ ). Obviamente, la imagen de los jóvenes, como de cualquier otro colectivo, en los medios no se traduce automáticamente en la generación de unos estereotipos o unos efectos determinados. El planteamiento conductista en la investigación en el terreno de los medios de comunicación ya hace tiempo que fue desplazado por el cognitivista o constructivista. La decodificación de un discurso no es simplemente una respuesta directa a los estímulos sino que entran en juego esquemas previos a partir de experiencias personales, procesos de negociación de significados, el papel mediador de diferentes agentes de socialización, como la familia, la escuela o el grupo de iguales.

\subsection{Principios de actuación periodística: justicia y responsabilidad}

La ciudadanía tiene en los medios de comunicación (públicos y privados) los garantes para que su derecho legítimo a recibir una información libre y veraz (reconocido en la Declaración de los Derechos Humanos y, en el caso español, en el artículo 20 de la propia Constitución española) se vea satisfecho. La protección de este derecho se convierte en un elemento indispensable en cualquier sociedad democrática y la ausencia de él sitúa inevitablemente ese país en un régimen de falta de libertades (Aznarr ${ }^{18}$, 1999: 10). El ejercicio de la profesión periodística encuentra, sin embargo, algunas limitaciones cuando precisamente este derecho a informar ya la libre expresión colisiona con otros derechos individuales o colectivos básicos como son el honor, la imagen o la intimidad. Desde la deontología y la ética periodística existe una conciencia crítica sobre la necesidad de hacer una información responsable que se ajuste a los valores tradicionales del periodismo pero que a la vez no pise otros derechos. Habrá, por tanto, que dirimir en cada caso qué debe prevalecer.

La mayoría de códigos éticos y deontológicos de referencia que rigen la profesión periodística a nivel internacional, como la Resolución 1003 del Consejo de Europa, el código ético de la Federación Internacional de Periodistas o los Principios Periodísticos de la UNESCO formulados el año 1982, coinciden en la necesidad de equilibrar el derecho a la información con el de la privacidad, intimidad o respecto de los ciudadanos. En Cataluña el código deontológico de referencia es el elaborado por el Colegio de Periodistas de Cataluña del año 1992 que recoge unos principios similares. En una propuesta de taxonomía de estos principios periodísticos deontológicos propuesta por Salvador Alsius ${ }^{19}$ (1998), se pueden clasificar los valores éticos que se encuentran transversalmente en la mayoría de códigos periodísticos de todo el mundo en cuatro grupos: verdad, libertad, responsabilidad y justicia.

Cuando hablamos del tratamiento informativo de colectivos específicos, como pueden ser en este caso los jóvenes, hay que buscar en el apartado de justicia las recomendaciones de cara a hacerles un tratamiento que sea el más adecuado posible. Este principio no consiste en ser "justo" en cierto sentido sino en favorecer que aquellos grupos sociales que parten con desventaja -y que tienden a tener una representación distorsionada en el escenario mediático (Alsius ${ }^{20}, 2010$ ) - puedan recibir desde los medios un trato positivo o adecuado que contribuya a modificar o transformar la percepción social que de ellos se tiene. Son lo que llamamos "colectivos socialmente desfavorecidos" como las mujeres, los inmigrantes o los homosexuales entre otros. Es frecuente encontrar en códigos deontológicos nacionales e internacionales referencias directas para dispensar un tratamiento justo (bien igualitario, bien 
compensatorio) a algunos de estos colectivos (Aznar ${ }^{21}$, 1999). En cambio, en el caso de los jóvenes estas guías son casi inexistentes debido a la propia transversalidad y hetereogeneidad del colectivo pero también por la falta de una percepción social de las personas jóvenes como grupo en peligro o con necesidad de una especial protección.

\subsection{Las rutinas de producción periodística}

Antes de analizar el tratamiento informativo que reciben las personas jóvenes es necesaria una aproximación a las rutinas de producción periodística y otros conceptos profesionales (géneros, fuentes,...) que influyen y condicionan el contenido informativo, elementos que permiten entender mejor algunos aspectos clave en el funcionamiento de los medios. La noticia es una construcción social de la realidad y los que la construyen forman parte de un proceso de socialización que les permite determinar, ante los acontecimientos que viven, qué es y qué no es noticia (Tuchman $\left.{ }^{22}, 1983\right)$. La misma dinámica de funcionamiento de las empresas mediáticas es la que marca el conjunto de acciones y normas que configuran las rutinas de producción. Y es en las formas o rutinas de producción de las noticias donde se encuentran los factores que acaban determinando qué eventos deben ser noticiables y como lo deben ser.

Estas lógicas de funcionamiento de los medios y las rutinas no facilitan un trabajo de contextualización de la información. La necesidad de comprimir la realidad en un número muy limitado de líneas o minutos y con una limitación de tiempo muy acusada tanto para elaborar como para difundir las informaciones lleva inevitablemente a la simplificación (Figueras $\left.{ }^{23}, 2010\right)$. Todo ello puede conducir a situaciones de espectacularización, vulgarización, simplificación y personalización de las noticias, algo que no ayuda, al contrario agrava, los posibles casos de esterotipación de colectivos. La construcción de los titulares, principal ejemplo de este afán sintetizador del periodismo, es un buen indicador para analizar si se construyen relatos periodísticos simplificadores que puedan tender a la creación de estereotipos.

Los mismos códigos deontológicos que se han mencionado hablando de los principios éticos contienen también apelaciones específicas a un uso cuidadoso de las fuentes informativas para realizar un periodismo riguroso y responsable. No en vano, las fuentes representan la espina dorsal de la información, un elemento capital de las noticias sin las cuales difícilmente se podrían elaborar: los medios de comunicación de más prestigio son los que están mejor informados, y normalmente los medios mejor informados son los que disponen de unas fuentes informativas de mayor calidad. La selección de las fuentes más adecuadas para cada información, el uso que se hace de estas fuentes y la relación que el periodista tiene con ellas exige un grado muy elevado de compromiso del profesional con la verdad y la responsabilidad (Martínez-Fresneda ${ }^{24}, 2004: 260$ ). El buen uso y contraste de la fuentes periodísticas, aunque es una cuestión clásica de la profesión, todavía se percibe como una de las preocupaciones principales entre los profesionales (Maciá y Herrera ${ }^{25}, 2010$ ). Una práctica profesional que respete el principio de justicia antes mencionado deberá procurar que las distintas visiones de una notícia o partes de un conflicto estén debidamente representadas en la notícia a través de fuentes diversas que permitan ofrecer una información plural. La dependencia excesiva de fuentes oficiales o de agencia no sólo afecta al pluralismo informativo (se repiten temas y hasta textos) sino que "refueza también estereotipos" (Gelado $\left.{ }^{26}, 2009\right)$. 


\section{Objetivos y metodología}

El objetivo de este artículo es presentar los datos del estudio que permiten cuantificar, por un lado, la presencia o ausencia de jóvenes en los medios de comunicación. Por otro lado, se busca saber cómo los periodistas construyen la información sobre personas jóvenes a partir del análisis de las fuentes utilizadas, los géneros periodísticos, la manera cómo se titula y la propia actitud que toma el narrador-periodista cuando da a conocer hechos protagonizados por personas jóvenes. Además, se pretende averiguar la percepción que los agentes de juventud tienen de la imagen de la juventud en los medios y del proceso de elaboración de la información.

Para lograr estos objectivos se optó por el análisis de contenido. Esta técnica de investigación ha sido muy utilizada en la investigación científica de los medios de comunicación porque es muy útil para describir de forma objetiva, sistemática y cuantitativa el contenido manifiesto de las comunicaciones (Berelson $\left.{ }^{27}, 1952\right)$ y porque se pueden, a partir de ciertos datos, hacer inferencias reproducibles y válidas (Krippendorff $\left.{ }^{28}, 1990\right)$. El análisis de contenido pone de manifiesto el sistema de valores y representaciones sociales de los mensajes que responden a las intenciones de los emisores, premeditadas o no.

En el estudio, por tanto, se realiza, por un lado, un análisis temática cuantitativa que permite describir sistemáticamente la presencia y ausencia de las categorías seleccionadas y, por otro, un análisis de contenido cualitativo que se enmarca en el construccionismo social de la realidad inspirado por Schütz ${ }^{29}$ (1972) y Berger y Luckman ${ }^{30}$ (1988). En la sociedad actual los medios de comunicación intervienen en la construcción de imágenes sobre la juventud, y utilizan estrategias argumentativas que si se analizan permite descubrir cómo se transmiten determinadas visiones.

La muestra seleccionada de medios informativos para analizar la han constituido los dos diarios de información general líderes en Cataluña (La Vanguardia, El Periódico de Catalunya); los dos gratuitos más leídos ( $A D N, 20$ Minutos); los dos digitales líderes (Vilaweb, 3cat24.cat); el diario local-comarcal general más leído (El Punt edición comarcas gerundenses); el gratuito local con mayor difusión (Més Tarragona); y el digital líder en su sector local (Osona.com). También se ha analizado la radio y televisión líderes (Catalunya Ràdio y Televisió de Catalunya). La selección se ha realizado a partir de los datos de la tercera oleada de resultados de octubre de 2008 del Barómetro de la Comunicación y la Cultura $^{31}$ aplicadas en el territorio de Cataluña.

El tiempo de estudio analizado comprende un año (segundo semestre 2008 - primer semestre 2009) y, en concreto, se han escogido dos muestras: una aleatoria (formada por tres semanas) y otra intencionada (dos eventos noticiables específicos sobre jóvenes). En la primera muestra se ha seleccionado las semanas del 29 de septiembre al 5 de octubre de 2008, del 2 al 08 de febrero de 2009 y del 20 al 26 de julio de 2009. La muestra aleatoria contempla el análisis de 20.121 noticias, de las cuales se han analizado las 1.399 que trataban sobre jóvenes ${ }^{32}$. La segunda muestra ha consistido en las dos noticias sobre jóvenes que tuvieron más eco mediático en el período analizado: por un lado, los exámenes de acceso a la universidad del (del 9 al 11 de junio de 2009) y, por otro, las protestas y desalojo de estudiantes de la Universidad de Barcelona contrarios al llamado Plan de Bolonia (del 18 al 21 de marzo de 2009). 
Para completar el estudio también se utilizaron otras metodologías de tipo cualitativo. Se realizaron cuatro entrevistas en profundidad: dos a profesionales del mundo de la comunicación (jefa de informativos de TV3 y redactora de Sociedad del diario gratuito 20minutos) y dos más a agentes del mundo juvenil (una concejala y un técnico de juventud de dos municipios de la provincia de Barcelona). Esta parte cualitativa también contó una entrevista en grupo. El objetivo era conocer la opinión de las dos partes afectadas sobre el trato que los medios dan a los jóvenes y averiguar, por un lado, el grado de sensibilidad/consciencia que los periodistas tienen de este trato y, por otro, la percepción que los agentes de juventud tienen del funcionamiento de esta cobertura informativa. En el grupo participaron ocho personas. Por la parte periodística: la jefa de edición de Els Matins de TV3, una redactora de El Matí de Catalunya Ràdio, un redactor de l'Agència Catalana de Notícies, el jefe de prensa de la empresa tecnológica EyeOs y a la vez redactor de Tele Cinco; y por la parte de profesionales de la juventud: técnica de la organización juvenil Diomira, técnica de juventud de una ayuntamiento de la provinciade Barcelona, un representante del Consell Nacional de la Joventut de Catalunya y un técnico de l'Observatori Català de la Joventut de la Generalitat de Cataluña ${ }^{33}$. En ambos casos se optó por aplicar estrategias no directivas: es decir, el guión era semiestructurado y organizado de lo más general a lo más específico. La estructura era flexible a partir de un esquema preestablecido con los temas que interesaban para dar respuesta a los objetivos de la investigación (Rubin y Rubin, 2005; King y Horrocks, 2010).

\section{Resultados}

A continuación se presentan los resultados del análisis de contenido y se complementan con algunas de las respuestas de las entrevistas para poder comprender mejor los datos y la percepción que sobre ellos tienen las dos partes implicadas.

\subsection{La presencia y perfil de las personas jóvenes en los medios}

Sobre un total de 20.121 piezas analizadas Sólo en un 7\% (1399) de las noticias que se publican en los 11 medios analizados hay presencia de personas jóvenes. La representación de los jóvenes es bastante homogénea en los medios analizados. Si al total de noticias sobre jóvenes se le quitan las de la sección de deportes, el porcentaje se reduce al $3 \%$ (579). Esto quiere decir que el $58,6 \%$ de las informaciones en las que aparecen personas jóvenes se encuentran en las páginas deportivas, mientras que el $41,4 \%$ restante tratan otros aspectos de la juventud.

Sin tener en cuenta la información deportiva, el número de personas jóvenes conocidas se eleva hasta el $12 \%$, por un $86 \%$ de personas anónimas y un $2 \%$ de indeterminado. Por medios, es en los medios audiovisuales e Internet donde la presencia de personas jóvenes famosas es más reducida con porcentajes que en ningún caso superan el $4 \%$. En cambio, la presencia de este colectivo es mucho más amplia entre la prensa de pago (sobre todo la de ámbito nacional) pero, sobre todo y de forma transversal, entre los diarios gratuitos que, en promedio, 1 de cada 4 jóvenes que salen en las noticias son personas conocidas o famosas.

Incluso aquellos hechos que tienen personas jóvenes como protagonistas y que pueden considerarse de especial relevancia informativa, tienen una presencia limitada en los medios (un 5,06\% las protestas contra Bolonia de marzo de 2009 y un 2,82\% los exámenes de Selectividad de junio de 2009). En los medios audiovisuales estos dos casos tienen más presencia que en los escritos. La prensa gratuita no destaca por encima de la de pago como 


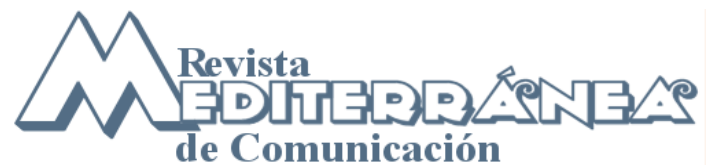

se podría pensar e incluso presenta cifras algo más bajas y la prensa local hace un tratamiento menor de estos casos. Destaca TV3, con un 22,7\% del tiempo dedicado al caso Bolonia y un $11,47 \%$ de dedicación al caso Selectividad. Probablemente varios factores inciden en este hecho. Las noticias en torno a los jóvenes generan más imágenes como manifestaba uno de los agentes de juventud en la entrevista en profundidad: "La imagen tiene más impacto, llama la atención, pero no es lo mismo el impacto de las imágenes positivas, que se interpretan como lo que es normal que pase y por tanto no llaman la atención, respecto al de las imágenes negativas que sí lo hacen”. Pero son las imágenes "negativas", como las del caso Bolonia, las que tienen una representación mayor en la televisión. La jefa de informativos de TV3 afirma, sin embargo, que los medios públicos no deben hacer "moralina" sino enseñar lo que existe y basta; según esta profesional no hay noticias negativas ni positivas y cree que si se muestra una imagen edulcorada, no mejorará la juventud: "Mostrar la realidad no tiene porque ser negativo". Y añade: "Ahora bien, no tenemos que informar sólo del botellón, cuidan mucho la Selectividad, porque eso da la idea de cómo es la vida de diversa". Y es que el tratamiento cuantitativo de este caso comparado con el resto de medios también sitúa TV3 en el primer lugar.

Otro de los agentes de juventud, sin embargo, no comparte esta visión ya que considera que las noticias que siempre salen sobre jóvenes "son disturbios, el día mundial contra el alcohol o el botellón". Según este profesional "salen mucho los problemas de convivencia en el espacio público porque molesta que los jóvenes lo ocupen, como si no hicieran nada". Admite que "hay actos de violencia, pero hay muchos jóvenes en el mundo que hacen muchas cosas y en estos casos la cobertura es muy puntual".

\subsection{Las noticias sobre jóvenes en titulares y portadas}

Un indicador que es esencial para poder analizar hasta qué punto las noticias sobre personas jóvenes tienen más o menos relevancia en el medio que las publica-o el tratamiento que se hace-es la observación de la presencia de estas noticias en los sumarios o portadas de los mismos medios. La aparición (o no) en estos espacios puede dar a entender la importancia que desde el medio se da al colectivo. El resultado de esta observación es bastante concluyente: el $82 \%$ de las noticias analizadas no aparecen en los sumarios o portadas por un $15 \%$ que sí lo hacen.

Tabla 1. Aparición en portada/sumario de jóvenes (porcentaje). Cataluña, 2008 y 2009

\begin{tabular}{cc}
\hline & Porcentaje \\
SI & $15 \%$ \\
No & $82 \%$ \\
Indeterminado & $3 \%$ \\
\hline Fuente: elaboración propia
\end{tabular}

Si se centra el análisis no ya en las portadas o sumarios sino en las propias piezas redaccionales, se puede observar cómo en poco más de una cuarta parte de las noticias analizadas $(28 \%)$ el titular de la misma contiene de forma específica una referencia sobre la condición de joven de los protagonistas de aquel hecho, mientras que en el $72 \%$ de las piezas esta referencia no está. Uno de los periodistas confirma en la entrevista en profundidad que la forma de titular condiciona también la imagen de la juventud ya que los medios van a buscar el título "que enganche más". Y añade: "Los ganchos que se buscan, sobre todo en la prensa gratuita, se llevan demasiado al extremo aunque no llegan al sensacionalismo (...). Estigmatiza no conscientemente pero es que eso vende más". "Buscar 


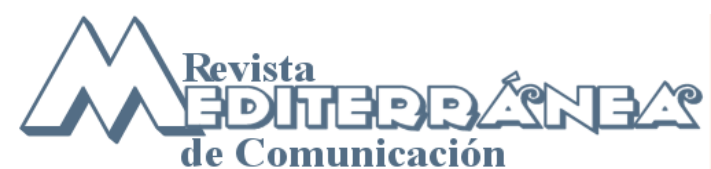

ISSN 1989-872X - Año3 (2012), pp. 39-58

el gancho siempre será algo negativo-continúa la periodista-. La gente lo leerá seguro, acabará vendiendo. Son dinámicas inherentes al periodismo". En cambio, la escasa presencia del adjetivo joven en los elementos de titulación se explica, según otro de estos profesionales, porque desde los medios se ha intentado ir quitando la palabra 'joven' de las noticias con la voluntad de no añadir elementos estereotipadores al adjetivo.

Tabla 2. Mención explícita de la condición de joven en titulares (porcentaje). Cataluña, 2008 y 2009

\begin{tabular}{rc}
\hline & Porcentaje \\
SI & $28 \%$ \\
No & $72 \%$ \\
\hline
\end{tabular}

Fuente: elaboración propia

En cuanto a la titulación, todos los medios tienen un comportamiento similar coincidente con los datos globales ahora mencionados con la salvedad de los diarios digitales donde casi la mitad de las noticias sobre jóvenes (48\%) mencionan de forma explícita en el titular la condición juvenil de aquella información o de los protagonistas de la misma.

Estos datos generales sobre la poca mención de la condición juvenil en los titulares de las noticias no sólo no quedan matizadas o corregidas sino del todo corroboradas si se analizan subtítulos, antetítulo u otros elementos de titulación de las informaciones. Los datos son, casi, calcados: en el $71 \%$ de las piezas analizadas no hay ninguna mención explícita de la condición de joven en estos otros elementos de titulación, por un $28 \%$ de las noticias en que sí que aparece esta referencia.

La presencia de las noticias que tratan sobre los casos analizados en los sumarios o portadas de los medios es de algo más de un $60 \%$ en ambos casos. Así, si se compara con el $15 \%$ de presencia en las portadas y sumarios del conjunto de noticias sobre jóvenes se puede afirmar que cuando se trata de casos de especial relevancia informativa juvenil, los medios jerarquizan al alza y destacan estos hechos. Obviamente, hay que decir que no se puede analizar esta cuestión aisladamente porque el criterio de jerarquización de los medios depende de la agenda informativa del día.

A diferencia de lo que se observaba en el análisis de las semanas aleatorias, donde sólo en el $28 \%$ de los titulares se mencionaba la palabra 'joven', 'juventud' o sinónimos, en los casos estudiados este uso explícito aumenta hasta el $60 \%$ (en el caso de Bolonia) o el $69 \%$ (en las noticias de Selectividad).

Algunos ejemplos parecen corroborar este punto de vista. En una crónica del diario La Vanguardia sobre los enfrentamientos entre Mossos d'Esquadra y estudiantes en el caso Bolonia, se observa una distinción clara antro el uso de la palabra estudiantes y el uso de la palabra jóvenes para definir los mismos grupos de personas en función de la acción que realizan. Encontramos jóvenes que denuncian, insultan y se enfrentan, mientras son estudiantes los que dicen, se manifiestan o lloran. Son jóvenes los que llegan cuando la tensión sube, mientras que son estudiantes los que salen cuando sorprende la contundencia de una carga policial. Parece que se les define como jóvenes cuando la acción tiene connotaciones negativas y como estudiantes cuando son víctimas o la frase tiene connotaciones neutras. 


\subsection{Los géneros informativos}

La gran mayoría de las piezas sobre jóvenes analizadas en este estudio (tres de cada cuatro, o lo que es lo mismo, el $75 \%$ ) pertenecen al género informativo. El $15 \%$ son textos de opinión mientras que el $8 \%$ son piezas interpretativas por tan sólo el $2 \%$ de noticias que hay que inscribirse en el género híbrido.

Tabla 3. Géneros de las noticias de jóvenes (porcentaje). Cataluña, 2008 y 2009.

\begin{tabular}{cc}
\hline Género & Porcentaje \\
Informativo & $75 \%$ \\
Interpretativo & $8 \%$ \\
Argumentativo & $15 \%$ \\
Híbrido & $2 \%$ \\
\hline Fuente: elaboración propia
\end{tabular}

Estos datos son bastante transversales ya que se observan pocas diferencias cuando se analiza al detalle medio por medio. Según uno de los agentes de juventud entrevistados hay poca presencia de piezas argumentativas y cuando se hace es con una actitud negativizadora o simplista: "En algunas noticias hay columnas de expertos, pero cuando son [informaciones] de jóvenes, se opta por la vertiente [de opinión] sensacionalista. Hay una actitud proactiva. Los porqués. Que la gente pueda reflexionar".

\subsection{Las fuentes informativas}

El análisis del uso de las fuentes informativas permite saber cómo han accedido los periodistas a la información que acaban elaborando. El 34\% de las piezas analizadas están construidas a partir de fuentes primarias, o sea, en base declaraciones o entrevistas a los protagonistas de los hechos $\mathrm{y} / \mathrm{o}$ a partir de la propia observación, conocimiento 0 investigación del periodista. Sin embargo, un porcentaje casi idéntico de las noticias (el $33 \%$ ) están basadas en fuentes institucionales: por lo tanto, es a partir de declaraciones oficiales, ruedas de prensa o comunicados de instituciones como se construye un tercio de las piezas que hablan de personas jóvenes. 2 de cada 10 textos se hacen en base a fuentes expertas, personas que son consultadas por su conocimiento del ámbito temático específico (en este caso, la juventud u otros temas que en un hecho concreto se relacionan con la juventud). Finalmente, en un $13 \%$ de las piezas analizadas la información se obtiene a partir de despachos de agencias de información.

Tabla 4. Tipología de las fuentes en la noticias de jóvenes (porcentaje). Cataluña, 2008 y 2009.

\begin{tabular}{cc}
\hline Tipo de fuente & Porcentaje \\
Fuente primaria & $34 \%$ \\
Fuente expert & $20 \%$ \\
Fuente institucional & $33 \%$ \\
Fuente de agencia & $13 \%$ \\
\hline
\end{tabular}

Fuente: elaboración propia

Por grupos de medios se observan comportamientos sensiblemente diferenciados: los medios digitales son los que más utilizan fuentes institucionales (50\% de sus piezas) mientras que son los que menos fuentes primarias tienen (25\%) y los únicos que no utilizan 
de Comunicación

información de agencia. En los diarios impresos de pago también son mayoritarias las fuentes institucionales (41\%) y, por el contrario, es donde porcentualmente menos fuentes expertas hay (12\%). Las fuentes primarias (35\%) y las fuentes de agencias (12\%) están presentes en unos porcentajes idénticos a los registrados en los diarios impresos gratuitos que, a su vez, hacen un $29 \%$ de las piezas con fuentes institucionales y un $24 \%$ con expertos.

Tabla 5. Tipología de fuentes en noticias de jóvenes según tipología de medios (porcentaje). Cataluña, 2008 y 2009.

\begin{tabular}{cccc}
\hline Tipo de fuente & $\begin{array}{c}\text { Periódicos } \\
\text { gratuitos }\end{array}$ & $\begin{array}{c}\text { Periódicos de } \\
\text { pago }\end{array}$ & $\begin{array}{c}\text { Periódicos } \\
\text { digitales }\end{array}$ \\
Fuente primaria & $35 \%$ & $35 \%$ & $25 \%$ \\
Fuente expert & $24 \%$ & $12 \%$ & $25 \%$ \\
Fuente institucional & $29 \%$ & $41 \%$ & $50 \%$ \\
Fuente de agencia & $12 \%$ & $12 \%$ & $0 \%$ \\
\hline
\end{tabular}

Fuente: elaboración propia

La capacidad de los jóvenes (y las entidades y asociaciones juveniles) de convertirse en una fuente principal para los periodistas a la hora de tratar según qué temas es clave para la imagen que los propios jóvenes proyectan en los medios, tal y como opina uno de los agentes del mundo juvenil en una entrevista en profundidad, aunque también advierte que a pesar del esfuerzo por dar información a los medios, ellos la pueden utilizar (o "sesgar", en palabras suyas) según como crean.

Es muy significativo destacar que el $79 \%$ de las noticias que tratan sobre personas jóvenes no utilizan ninguna fuente joven para elaborar la información. El 21\% sí tienen en cuenta estas fuentes. Sobre este $20 \%$, en el $84,6 \%$ de los casos analizados la fuente es consultada o tenida en cuenta por su condición juvenil, es decir, que el hecho de que se trate de una persona joven es lo que motiva al periodista a tenerla en cuenta a la hora de elaborar la información en cuestión. Los periodistas corroboran estas cifras al afirmar que "faltan fuentes primarias o calificadas para hablar de los jóvenes". También apuntan que "sólo se va a buscar a los agentes de juventud cuando hace falta un perfil de joven muy concreto, del estilo: necesitamos un joven precario. $Y$ en cambio es difícil aparecer en los medios para explicar las acciones positivas que se desarrollan en el ámbito institucional o asociativo". Desde el ámbito de la juventud se lamenta, en una de las entrevistas en profundidad, que "todos hablamos de ellos [los jóvenes] pero con ellos no habla nadie" ya que, según ella, "es más fácil hacer una noticia así que hacer un trabajo de reflexión y hablar con ellos".

La presencia de fuentes jóvenes es bastante homogénea en todos los medios, moviéndose con unas cifras medias de entre el 15 y el $25 \%$, con la excepción de los medios públicos: en el $55 \%$ de las noticias de TV3 se usan fuentes jóvenes, un porcentaje que sube 5 puntos más (hasta el 60\%) en el caso de Catalunya Ràdio.

En cuanto al uso de fuentes jóvenes en los dos casos analizados, la conclusión básica es que cuando los medios tratan un "tema joven" suelen buscar alguna fuente joven, pero proporcionalmente la presencia de éstas es bastante pequeña respecto al total de fuentes utilizadas. En el caso Bolonia sólo utilizan un $27 \%$ de fuentes jóvenes y en el de la Selectividad, un 37\%. Cuando el caso conlleva conflictividad como es Bolonia, se utilizan 


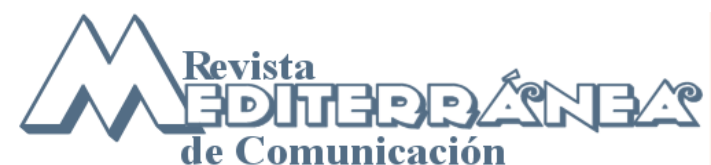

ISSN 1989-872X - Año3 (2012), pp. 39-58

menos fuentes jóvenes, reforzando una mirada externa, probablemente más institucional y más paternalista, en definitiva, una mirada más problematizadora.

Tabla 6. Uso de fuentes jóvenes en los caso Boloña y Selectividad (porcentaje). Catalunya, 2008 y 2009.

\begin{tabular}{ccc}
\hline Fuente joven & $\begin{array}{c}\text { Caso } \\
\text { Selectividad }\end{array}$ & Caso Boloña \\
& & \\
$\mathrm{Si}$ & $37 \%$ & $27 \%$ \\
$\mathrm{No}$ & $63 \%$ & $73 \%$ \\
\hline \multicolumn{3}{c}{ Fuente: elaboración propia }
\end{tabular}

Uno de los periodistas entrevistados lo explica así: "Intentas dar la imagen real de los jóvenes protagonistas, hablar con ellos de primera mano. Ahora, a veces te quedas con el discurso oficial por las propias dinámicas profesionales: somos pocos, llega la hora de cierre y muchas veces no puedes hacer más ".

\subsection{La actitud del narrador}

La actitud que el narrador-periodista toma ante el hecho informativo puede ser clave para comprender el tratamiento que el medio da, en este caso, a las personas jóvenes. Para analizar esta cuestión se categorizaron tres posibles actitudes del periodista ante los jóvenes reflejadas en la noticia: neutral, positiva (que manifiesta o da un mensaje favorable) o negativa (que manifiesta o da un mensaje no favorable). El análisis de contenido permitió estudiar, pieza por pieza, esta actitud del narrador. Se buscaron principalmente adjetivos, advervios o expresiones referidas a los protagonistas jóvenes de las noticias que pudieran demostrar una actitud $u$ otra por parte del periodista.

Con este análisis se pudo establecer que el $15 \%$ de las personas jóvenes que aparecen en las noticias están representadas de una forma positiva. En cambio, el 19\% aparecen con connotaciones negativas. Sin embargo, el grupo mayoritario lo representa el $66 \%$ de las noticias en que los jóvenes reciben un tratamiento informativo neutro.

Tabla 7. Actitud del narrador respecto a las personas jóvenes representades en los medios de comunicación (porcentaje). Cataluña, 2008 y 2009.

\begin{tabular}{cc}
\hline Actitud del narrador & Porcentaje \\
Positiva & $15 \%$ \\
Negativa & $19 \%$ \\
Neutra & $66 \%$ \\
\hline
\end{tabular}

Fuente: elaboración propia

En referencia a los casos, en el de la Selectividad la actitud del narrador es casi neutra en su totalidad. En el caso de Bolonia la mayor parte de noticias muestran una actitud del narrador neutra, pero en un $7 \%$ es positiva y en un $28 \%$ negativa, un porcentaje muy significativo. Una de las periodistas entrevistadas, en relación a esta cuestión, señaló que "en las manifestaciones de Bolonia nunca se ve en positivo una protesta y aunque es lícito quejarse se vio como un tema de violencia". Y concretaba: "Yo en mi diario no encuentro, 


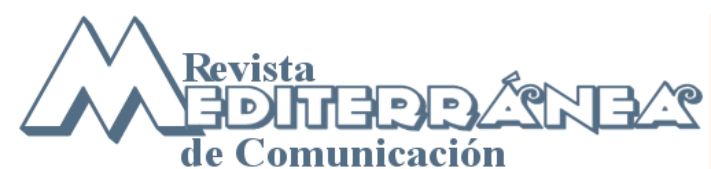

ISSN 1989-872X - Año3 (2012), pp. 39-58

pero con las manifestaciones de estudiantes hubo consignas [por parte de las direcciones de los medios]".

\subsubsection{Joven individual o juventud colectiva}

Si nos centramos en cómo varía la actitud del narrador según hace referencia a las personas jóvenes como individuos o como conjunto, se observa que el relato periodístico varía de forma significativa. El narrador mantiene una actitud positiva frente al $23 \%$ de los jóvenes que aparecen en las noticias analizadas de forma individual mientras que este porcentaje baja hasta el $8 \%$ en el caso de los jóvenes cuando son representados como grupo. Las diferencias con la actitud negativa también son relevantes: el $26 \%$ de los jóvenes que aparecen como parte de un grupo, son representados de forma negativa, mientras que sólo lo son el $13 \%$ de los que salen en las noticias de forma individual. Estas cifras corroboran la percepción que uno de los agentes de juventud exponía en la entrevista en profundidad cuando apuntaba que los jóvenes son percibidos desde los medios como un problema y vistos como un colectivo aislado de la sociedad. Una idea similar, que coincide con los datos expuestos, la manifiesta uno de los otros entrevistados del mundo juvenil que lamenta que los jóvenes sólo salgan en los medios a título individual "cuando es algo muy positivo como un joven investigador" pero en cambio, apunta, no salen historias de reconocimiento de jóvenes anónimos.

Sin embargo, hay que decir que en ambas situaciones el periodista se mantiene neutro en unos porcentajes elevados y casi idénticos (el 64\% de las noticias sobre jóvenes individuales y el $66 \%$ sobre colectivos). Finalmente, cabe destacar que no se observan diferencias significativas entre medios en este ámbito de análisis concreto.

Tabla 8. Actitud del narrador ante el individuo/colectivo joven (porcentaje). Cataluña, 2008 y 2009.

\begin{tabular}{ccc}
\hline $\begin{array}{c}\text { Actitud del } \\
\text { narrador }\end{array}$ & Individuo & Colectivo \\
& & \\
Positiva & $23 \%$ & $8 \%$ \\
Negativa & $13 \%$ & $26 \%$ \\
Neutra & $64 \%$ & $66 \%$ \\
\hline
\end{tabular}

Fuente: elaboración propia

\subsubsection{Tema de la noticia}

Los datos confirman que es relevante la actitud que el periodista mantiene ante las noticias que afectan a algunos de los temas que más concentran la presencia de jóvenes (violencia y accidentes) o aquellos que se consideran de interés estructural para el colectivo juvenil (emancipación, educación, precariedad y asociacionismo).

Es interesante comprobar como en el $46 \%$ de las informaciones sobre jóvenes que tratan sobre violencia la actitud del narrador es negativa, mientras que en el $54 \%$ restante se mantiene una posición neutra. No hay ninguna noticia que mezcle jóvenes y violencia donde el periodista haga valoraciones positivas hacia los jóvenes protagonistas. Las posiciones son menos divergentes cuando el tema de la pieza es la emancipación. En este caso, la mayoría de narradores adoptan una actitud neutra (en un $42,8 \%$ de los casos) mientras que en el resto de noticias encontramos unos porcentajes idénticos de posiciones positivas y 
negativas (28,6\%). Cuando se habla de educación, la visión neutra vuelve a tomar fuerza $(71,4 \%)$ si bien la posición negativa es también relevante $(19,5 \%)$, muy superior a la actitud positiva $(9,1 \%)$. En cambio, cuando se habla de asociacionismo la negatividad del narrador desaparece completamente y las piezas son mayoritariamente neutras $(77,7 \%)$ pero con una importante presencia de noticias de tono positivo (22,3\%). También son ampliamente neutras (72\%) las noticias sobre jóvenes y accidentes o desastres, con un porcentaje reducido de negatividad (10\%) y un $18 \%$ de actitud positiva. En cambio, cuando el tema a abordar es la precariedad laboral, curiosamente la actitud del narrador es negativa en 8 de cada 10 noticias que tratan la cuestión y neutra en las piezas restantes.

Estas cifras dispares con visiones positivas y negativas son confirmadas por los periodistas cuando explican que, más que una actitud a favor o en contra por parte de los medios, la imagen de los jóvenes "tiende a ser extremista": o bien las noticias de la juventud son muy negativas o, cuando se quiere poner algún joven como ejemplo social, son demasiado positivas.

Tabla 9. Actitud del narrador según el tema relacionado con jóvenes (porcentaje). Cataluña, 2008 y 2009

\begin{tabular}{ccccccc}
\hline $\begin{array}{c}\text { Actitud del } \\
\text { narrador }\end{array}$ & Accidentes & Precariedad & Asociacionismo & Educación & Emancipación & Violencia \\
Positiva & $18 \%$ & $0 \%$ & $22.3 \%$ & $9.1 \%$ & $28.6 \%$ & $0 \%$ \\
Negativa & $10 \%$ & $80 \%$ & $0 \%$ & $19.5 \%$ & $28.6 \%$ & $46 \%$ \\
Neutra & $72 \%$ & $20 \%$ & $77.7 \%$ & $71.4 \%$ & $42.8 \%$ & $54 \%$ \\
\hline
\end{tabular}

Fuente: elaboración propia

Si se analizan los datos que ofrecen el conjunto de medios agrupados según la tipología, se pueden observar algunas cuestiones interesantes. En el caso de la prensa de pago es donde más se observa una actitud del narrador negativa ante según qué temas, seguramente debido a que es en estos medios donde más piezas de opinión suele haber. Si bien en general la actitud neutra es la más común, hay varias ocasiones en que la situación no sigue este patrón general como por ejemplo cuando se habla de precariedad laboral o violencia, en cambio, la posición del periodista es positiva hacia el joven cuando se tratan temas como el asociacionismo.

Uno de los periodistas entrevistados, menor de 30 años, considera que el tratamiento de las piezas "va muy relacionado con la media de edad del redactor". Apunta que "hay medios que tienen plantillas muy jóvenes y eso se nota a la hora de enfocar los temas". En cambio considera que desde cierta prensa se mantiene una actitud hacia el joven que suele ser "paternalista".

Tabla 10. Actitud del narrador según el tema relacionado con jóvenes en medios de pago (porcentaje). Cataluña, 2008 y 2009

\begin{tabular}{ccccccc}
\hline $\begin{array}{c}\text { Actitud del } \\
\text { narrador }\end{array}$ & Accidentes & Precariedad & Asociacionismo & Educación & Emancipación & Violencia \\
Positiva & $26.4 \%$ & $0 \%$ & $22.2 \%$ & $16.3 \%$ & $0 \%$ & $0 \%$ \\
Negativa & $17.6 \%$ & $67 \%$ & $0 \%$ & $10.2 \%$ & $50 \%$ & $57.1 \%$ \\
Neutra & $55.9 \%$ & $33 \%$ & $77.8 \%$ & $73.5 \%$ & $50 \%$ & $42.9 \%$ \\
\hline
\end{tabular}

Fuente: elaboración propia 
Entre la prensa gratuita, la carga negativa es mucho menor, pero también es casi inexistente la actitud positiva por parte del narrador. La actitud que mantiene este tipo de prensa es criticada especialmente por los profesionales de la información entrevistados ya que encuentran paradójico que este tipo de medios, que son - a su juicio- los más consumidos por jóvenes y que tienen redacciones y consejos de redacción, a menudo, formados por periodistas más jóvenes, sean los que más fomentan los estereotipos y estigmatizaciones hacia su propio grupo de edad.

Tabla 11. Actitud del narrador según el tema relacionado con jóvenes en medios gratuitos (porcentaje). Cataluña, 2008 y 2009

\begin{tabular}{ccccc}
\hline $\begin{array}{c}\text { Actitud del } \\
\text { narrador }\end{array}$ & Accidentes & Educación & Emancipación & Violencia \\
Positiva & $0 \%$ & $13.3 \%$ & $0 \%$ & $0 \%$ \\
Negativa & $0 \%$ & $46.6 \%$ & $0 \%$ & $38.1 \%$ \\
Neutra & $100 \%$ & $40.1 \%$ & $100 \%$ & $61.9 \%$ \\
\hline
\end{tabular}

Fuente: elaboración propia

En todas las noticias analizadas sobre temas de educación y desastres o accidentes en prensa digital se observa como la actitud del narrador siempre es neutra. En cambio, cuando la temática versa sobre violencia, la neutralidad sigue siendo mayoritaria $(77,3 \%)$, pero la carga negativa del narrador hace acto de presencia de forma significativa $(22,7 \%)$.

La actitud del narrador que se puede observar ante ciertos temas en las noticias que aparecen en la radio y la televisión públicas es neutra en términos generales. Es destacable señalar que cuando se habla de precariedad, de nuevo la totalidad de las noticias analizadas mantienen una actitud positiva. En último término, cuando los temas son los desastres o accidentes o la violencia, la actitud neutra es la habitual en casi 9 de cada 10 noticias $(87,5 \%$ y $93 \%$, respectivamente) mientras que en las piezas restantes se impone una actitud negativa por parte del narrador.

\section{Discusión}

En las últimas décadas la profesión periodística ha ido incorporando el concepto de responsabilidad social en su forma habitual de actuación. La preocupación por ofrecer al lector/espectador un buen producto periodístico (riguroso, veraz, interesante...) se ha visto acompañado cada vez más de una preocupación por realizar un periodismo ético, responsable y respetuoso con los ciudadanos, como afirman la mayoría de los periodistas entrevistados. Esta mirada hacia adentro de la profesión ha sido elemental para poder atender (y entender) las llamadas que diversos colectivos han ido realizando a la profesión periodística en busca de un trato mediático respetuoso. Si bien es cierto que muchos medios no cumplen la función deontológica que de ellos cabría esperar, también lo es que la preocupación por estos valores periodísticos está muy presente en la profesión.

Los jóvenes han sido uno de los últimos colectivos que ha reclamado un trato más justo de los medios pero ello no se ha visto traducido en España en un elevado número de investigaciones, y las que se han realizado, han sido parciales. En este trabajo se han 


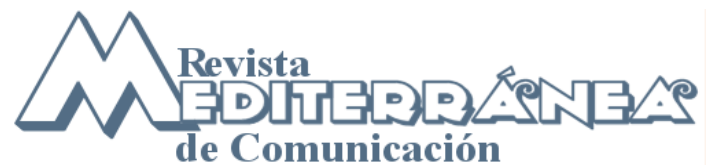

ISSN 1989-872X - Año3 (2012), pp. 39-58

analizado todos los medios de comunicación líderes en Cataluña, incluidos la prensa gratuita, local e internet.

Esta crítica a un supuesto tratamiento informativo parcial y poco riguroso del colectivo juvenil ha sido secundada, en los últimos años, por diversos agentes, especialmente por el asociacionismo juvenil. Otro de los movimientos actuales que ha sido especialmente crítico con la imagen proyectada los medios de comunicación ha sido el 15M. El estudio es previo a las movilizaciones pero ratifica la crítica al trato que los jóvenes reciben de los medios. El estudio realizado permite afirmar que, al menos, la queja por una infrarrepresentación de la juventud está fundamentada: la población joven disfruta de poca visibilidad informativa. Las informaciones en las que aparecen personas jóvenes representan el $7 \%$ del total de noticias publicadas. Y si se excluye la sección de deportes, estas se reducen al 3\%. Si se tiene en cuenta que en 2009 había 1.279.950 personas jóvenes (de entre 15 y 29 años) en Cataluña, que representaban el $17,29 \%$ de la población del país, se puede concluir que hay una diferencia muy significativa entre el número de jóvenes en la sociedad y la presencia de este grupo de edad en las noticias de los medios.

Ahora bien, hay que analizar los datos de la presencia de los jóvenes en los medios con prudencia, especialmente al compararlas con su peso en el conjunto de la población. Esta reducida visibilidad no implica que necesariamente haya que equiparar la cifra obtenida de presencia de personas jóvenes en los medios con el porcentaje que representan dentro de la sociedad, ya que intervienen muchos factores, especialmente de tipo periodístico. Ahora bien, la diferencia importante entre los dos datos lleva a pensar que los jóvenes pasan bastante desapercibidos en los medios y más si se tiene en cuenta que en este estudio no se han analizado sólo las noticias que se da voz a las personas jóvenes sino todas en las que aparecen, por accesoria que sea esta presencia. Es sintomático apreciar, por ejemplo, como las informaciones sobre jóvenes pasan desapercibidas en las portadas de diarios 0 sumarios de informativos ni tampoco se acostumbra a citar al colectivo en los titulares.

A pesar de los resultados del estudio, es difícil objetivar si existe una tendencia a la estigmatización de los jóvenes en los medios. Sin embargo, si se tiene en cuenta que las fuentes utilizadas para confeccionar las noticias con presencia de jóvenes son sobre todo institucionales y si se consideran las opiniones de periodistas y agentes de juventud (entrevistados en la fase cualitativa de la investigación), se puede afirmar que la reproducción de ciertos estereotipos sobre los jóvenes puede estar subjacente en las informaciones. Este fenómeno sitúa a los jóvenes, en cuanto a tratamiento mediático, en la misma situación que otros colectivos de los llamados "socialmente desfavorecidos".

Por las propias rutinas profesionales descritas en el marco teórico, el tratamiento periodístico de estos colectivos puede tender a ser poco reflexivo, basado en la reiteración de una determinada imagen sesgada o la vinculación a unas temáticas concretas. Pero, a pesar de todo, la actitud con que se habla de las personas jóvenes es mayoritariamente neutra. Sin embargo, los casos donde no lo es se observa una cierta bipolarización, que consiste en un tratamiento más positivo cuando se habla de un individuo y más negativo cuando la noticia se refiere a un grupo de jóvenes o las personas jóvenes en general. La actitud del periodista hacia las personas jóvenes también acostumbra a ser negativa cuando aborda temas como la violencia y en cambio cuando se habla de asociacionismo o emancipación es positiva. Como se desprende de las entrevistas a profesionales de la comunicación, no se trata de una voluntad intencionada de los medios de hacerlos aparecer en noticias negativas, sino que forma parte del propio funcionamiento profesional y de la necesaria jerarquización de las noticias que implica que muchos hechos no tengan cabida 


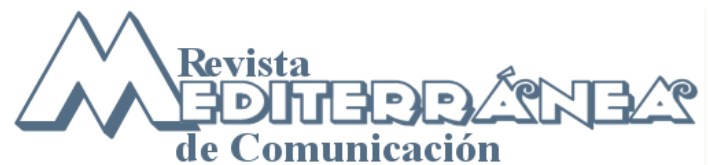

ISSN 1989-872X - Año3 (2012), pp. 39-58

en los espacios informativos. Pero la ausencia juvenil en otras informaciones de carácter más constructivo (noticias que tienen espacio en los medios de forma puntual) amplifica aún más esta negatividad mediática.

El uso concreto de la palabra joven no resulta neutro en las noticias analizadas sino que tiene un carácter de reclamo de excepcionalidad informativa. Tanto para lo positivo, como para lo considerado negativo, se utiliza la palabra joven, contribuyendo a esta visión dual de la juventud, idealizada como etapa de vida y estereotipada como colectivo que no encaja con lo que el mundo adulto espera. Esto conduce a una imagen de la juventud proyectada desde los medios que tiende a ser parcial y bipolar, o muy negativa (respecto al colectivo) 0 positiva (respecto individuos concretos).

Finalmente, cabe puntualizar, para no caer en una crítica poco cuidadosa, que en general el problema del tratamiento informativo de las personas jóvenes no es tanto cuantitativo como cualitativo. Es decir, si bien se detectan carencias a la hora de hacer información sobre la realidad de las personas jóvenes, son muy pocos los casos donde se percibe un tratamiento poco riguroso, simplista y estigmatizador de la juventud. Pero los medios son un gran altavoz que llega, quizás más que otros, al imaginario colectivo y esas pocas noticias pueden tener mucha más repercusión que muchas otras donde el tratamiento es equilibrado. Es lógico, por tanto, potenciar instrumentos y herramientas que contribuyan a evitar estos casos y, sobre todo, a aumentar la visibilidad de las personas jóvenes. De la misma manera que se ha hecho con otros colectivos sociales donde se constataba un tratamiento inadecuado por parte de los medios, es necesario que todos los actores implicados en este colectivo se comprometan a trabajar para cambiar la tendencia. Propuestas constructivas, y no sólo críticas al trabajo de los medios informativos, seguro que se valorarán positivamente en el mundo periodístico, que cada vez tiene más conciencia de su responsabilidad social. Ahora bien, el éxito de cualquier propuesta depende no sólo de los medios sino también de los propios periodistas que deben ver en el seguimiento a los valores éticos de la profesión una vía para fortalecer el periodismo.

Este trabajo es fruto del proyecto 'Medios de comunicación y jóvenes. Análisis de la situación, mecanismos de intervención y decálogo para un trato informativo adecuado de las personas jóvenes', dirigido por el Dr. Marcel Mauri y la Dra. Mònica Figueras, financiado por la Secretaria General de Joventut de la Generalitat de Cataluña, iniciado en 2009 y terminado en 2010.

\section{Bibliografía}

Alsius, S. (1998): Ėtica i periodisme. Barcelona: Pòrtic

Alsius, S. (ed.) (2010): The Ethical Values of Journalists. Field research among media professionals in Catalonia. Barcelona: Lexikon.

Aznar, H. (1999): Ética y periodismo. Barcelona: Paidós

Alcoceba, J. A., Cadilla, M. (dirs.) (2007): La Imagen de los Jóvenes en los Medios de Comunicación. Un Análisis Mediacional de las Noticias sobre Juventud publicadas en Prensa, Radio y Televisión durante los Meses de Octubre y Noviembre de 2006. Madrid: Instituto de la Juventud. 


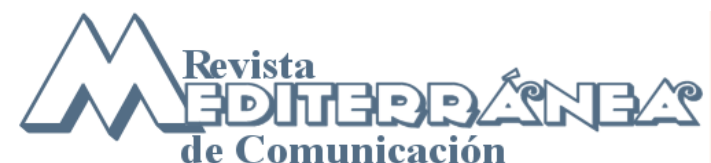

ISSN 1989-872X - Año3 (2012), pp. 39-58

Alcoceba, J. A. , Gladis, M. (2010): "El discurso mediático sobre los jóvenes en España. En Anuario electrónico de estudios en Comunicación Social, Vol. 3, №. 1.

Baca, V. (1998): Imágenes de los Jóvenes en los Medios de Comunicación de Masas, Madrid: Instituto de la Juventud-Fundación de Ayuda a la Drogadicción.

Bandura, A, Walters, R.H. (1980): Aprendizaje Social y Desarrollo de la Personalidad. Madrid: Alianza Universidad.

Berelson, B. (1952): Content Analysis in Communication Research. Glencoe: The Free Press.

Berger, P., y Luckmann, T. (1966): The Social Construction of Reality: A Treatise in the Sociology of Knowledge. Londres: Penguin.

Callejo, J. (2001): El grupo de discusión: introducción a una práctica de investigación. Barcelona: Ariel.

Casal, J., Merino, R., García, M. y otros (2004): Enquesta als Joves de Catalunya 2002, Generalitat de Catalunya, Barcelona.

Consell de l'Audiovisual de Catalunya (2009): La presència de les persones joves en la información. Informe sectorial trimestral. Barcelona: Generalitat de Catalunya.

Corbetta, P. (2003): Metodología y técnicas de investigación social. Madrid: Mcgraw Hill.

Devlin, M. (2005): "Teenage traumas. The discursive construction of young people as a 'problem' in an Irish radio documentary”. Young. Vol. 13, núm. 2, pp. 167-184.

Erikson, E. (1968): Identidad, Juventud y Crisis. Buenos Aires: Paidós.

Falchikov, N. (1986): "Images of Adolescence: An Investigation into the Accuracy of the Image of Adolescence Constructed by the British Newspapers". Journal of Adolescence.Vol. 1, núm. 9, pág. 167-80.

Feixa, C. (1993): La Joventut com a Metàfora. Sobre les Cultures Juvenils. Barcelona: Generalitat de Catalunya.

Feixa, C. (2006): De Jóvenes, Bandas y Tribus. Barcelona: Ariel.

Figueras, M. (2010): "El tratamiento informativo de los grupos socialmente desfavorecidos". A: Alsius, S; Salgado, F, (ed.) La ética informativa vista por los ciudadanos. Contraste de opiniones entre los periodistas y el público. Barcelona: Editorial UOC.

Gelado Marcos, R. (2009): "La dependencia de la prensa española hacia las agencias de noticias". Comunicación y Sociedad. Vol. XXII, núm. 2, pp. 243-276.

Giró, X. (2003): "La Imatge de la Joventut a la Premsa Escrita. Valors, política i violència". Anàlisi. Vol. 30, pp. 105. 


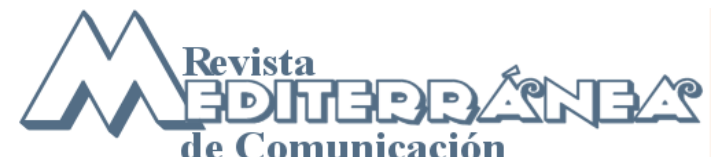

ISSN 1989-872X - Año3 (2012), pp. 39-58

King, N. y Horrocks, C. (2010): Interviews in Qualitative Research. Thousand Oaks CA: Sage Publications.

Krippendorff, K. (1990): Metodología de Análisis de Contenido. Teoría y Práctica. Barcelona: Paidós.

Lippmann, W. (1922): Stereotypes, Public Opinion and the Press. Nueva York: Mcmillan Publishing Co.

Lacalle, C. (2010): "Joves i ficció televisiva: representació i efectes". Anàlisi. Vol. 40, pp. 2945.

Luzón, V. y otros (2011): La Imagen de los/as Adolescentes en el Prime Time Televisivo. Transmisión, Consumo y Recepción, 2009 [online]. Instituto Nacional de la Mujer. [Fecha de consulta:10/11/2011]

Martín Serrano, M., Velarde, O. (2001): Informe Juventud en España 2000. Madrid: Ministerio de Asuntos Sociales, Instituto de Juventud.

Martínez Fresneda, H. (2005): Los Medios de comunicación a examen: una nueva perspectiva. Madrid: Universidad Francisco de Vitoria.

Merton, R.K.(1970): Social Theory and Social Structure, The Free Press, Glencoe.

Nilan P., Feixa C. (eds) (2006): Global Youth? Hybrid Identities, Plural Worlds. Londres/Nueva York: Routledge.

Pearson, G. (1983): Hooligan: A History of Respectable Fears. Londres: Macmillan.

Porteous, M.A., Colston, N.J. (1980): "How Adolescents are Reported in the British Press". Journal of Adolescence.Vol. 3, pp.197-207.

Rubin, H. y Rubin, I. (2004): Qualitative Interviewing: The Art of Hearing Data. Thousand Oaks (California): Sage Publications.

Ruiz Olabuénaga, J.I. (1996): Metodología de la investigación cualitativa. Bilbao: Universidad de Deusto.

Schütz, A. (1972): Fenomenología del Mundo Social. Buenos Aires: Paidós.

Tuchman, G. (1983): La Producción de la noticia: estudio sobre la construcción de la realidad. Barcelona: Gustavo Gili.

\footnotetext{
7. Notas

${ }^{1}$ El decálogo se puede encontrar en la web de la ahora Direcció General de Joventut: http://premsa.gencat.cat/pres fsvp/docs/2010/07/12/11/55/d63a40d6-baee-48fd-8a2a-b4dfc7a14051.pdf

${ }^{2}$ Cfr. MARTín SERRANO, M., VELARDE, O., Informe Juventud en España 2000, Ministerio de Asuntos Sociales, Instituto de Juventud, Madrid, 2001.

${ }^{3}$ Cfr. ERIKSON, E., Identidad, Juventud y Crisis, Paidós, Buenos Aires, 1968.
} 
${ }^{4}$ Cfr. CASAL, J., MERINO, R., GARCIA, M., QUESADA, M., Enquesta als Joves de Catalunya 2002, Generalitat de Catalunya, Barcelona, 2004.

${ }^{5}$ Cfr. FEIXA, Carles, La Joventut com a Metàfora. Sobre les Cultures Juvenils, Generalitat de Catalunya, Barcelona, 1993.

${ }^{6}$ Cfr. BANDURA, A, WALTERS, R.H., Aprendizaje Social y Desarrollo de la Personalidad, Alianza Universidad, Madrid, 1980.

${ }^{7}$ Cfr. LIPPMANN, Walter, Stereotypes, Public Opinion and the Press, Mcmillan Publishing Co., NewYork, 1922.

${ }^{8}$ Cfr. MERTON, R.K., Social Theory and Social Structure, The Free Press, Glencoe, 1970.

9 Cfr. FALCHIKOV, Nancy, "Images of Adolescence: An Investigation into the Accuracy of the Image of Adolescence Constructed by the British Newspapers", Journal of Adolescence, vol. 1, no. 9, 1986, pp. 167-80.

${ }^{10}$ Cfr. PORTEOUS, M.A., COLSTON, N.J., "How Adolescents are Reported in the British Press", Journal of Adolescence, vol. 3 , 1980, p.197-207.

${ }^{11}$ Cfr. DEVLIN, Maurice, "Teenage traumas. The discursive construction of young people as a 'problem' in an Irish radio documentary", Young, vol. 13 ํㅡ. 2, 2005, pp. 167-184

${ }^{12}$ Cfr. PEARSON, Geoffrey, Hooligan: A History of Respectable Fears, Macmillan, Londres, 1983.

${ }^{13}$ Cfr. BACA, V., Imágenes de los Jóvenes en los Medios de Comunicación de Masas, Instituto de la Juventud-Fundación de Ayuda a la Drogadicción, Madrid, 1998.

${ }_{14}^{14}$ Cfr. GIRÓ, Xavier, "La Imatge de la Joventut a la Premsa Escrita. Valors, política i violència", Anàlisi, vol. 30, 2003, p.105.

${ }^{15}$ Cfr. AlCoceBA, J. A., CADILLA, M. (dirs.), La Imagen de los Jóvenes en los Medios de Comunicación. Un Análisis Mediacional de las Noticias sobre Juventud publicadas en Prensa, Radio y Televisión durante los Meses de Octubre y Noviembre de 2006. Instituto de la Juventud, Madrid, 2007.

${ }^{16}$ Cfr. Consell de l'Audiovisual de Catalunya, La presència de les persones joves en la información, Informe sectorial trimestral, Generalitat de Catalunya, Barcelona, 2009.

${ }_{17}$ Cfr. LUZÓN, Virginia (coord.), CAPDEVILA, Arantxa., FERRER, I., FIGUERAS, Mònica., GÓMEZ, Lorena., JIMÉNEZ, Mònika., RAMAJO, J, La Imagen de los/as Adolescentes en el Prime Time Televisivo. Transmisión, Consumo y Recepción, 2009. http://www.inmujer.migualdad.es/mujer/muieres/estud inves/820.pdf (URL consultada septiembre 2011)

${ }^{18}$ Cfr. AZNAR, Hugo, Ética y periodismo. Paidós, Barcelona, 1999.

${ }^{19}$ Cfr. ALSIUS, Salvador, Ėtica i periodisme, Pòrtic, Barcelona, 1998.

${ }^{20}$ Cfr. ALSIUS, Salvador (ed.) The Ethical Values of Journalists. Field research among media professionals in Catalonia, Lexikon, Barcelona, 2010, p.108.

${ }_{21}$ Cfr. AZNAR, Hugo, Ética y periodismo. Paidós, Barcelona, 1999, p.240.

${ }^{22}$ Cfr. TUCHMAN, Gaye, La Producción de la noticia : estudio sobre la construcción de la realidad, Gustavo Gili, Barcelona, 1983.

${ }^{23}$ Cfr. FIGUERAS, Mònica, "El tratamiento informativo de los grupos socialmente desfavorecidos" en Alsius, S; Salgado, F, (ed.) La ética informativa vista por los ciudadanos. Contraste de opiniones entre los periodistas y el público, Editorial UOC, Barcelona, 2010.

${ }^{24}$ Cfr. MARTÍNEZ FRESNEDA, Humberto, Los Medios de comunicación a examen : una nueva perspectiva, Universidad Francisco de Vitoria, Madrid, 2005.

${ }^{25}$ Cfr. MACIÁ BARBER, C. y HERRERA DAMAS, S., "La deontología periodística: praxis, disfunciones y retos desde la perspectiva de los profesionales de la comunicación en la Comunidad de Madrid (2006-2009)" en: Comunicación y Sociedad, vol. XXIII, n. 1, 2010, pp.77-104.

${ }^{26}$ GELADO MARCOS, R..., "La dependencia de la prensa española hacia las agencias de noticias" en: Comunicación y Sociedad, vol. XXII, n. 2, 2009, p.243-276.

${ }^{27}$ Cfr. BERELSON, Bernard, Content Analysis in Communication Research, The Free Press, Glencoe, 1952, p.18.

${ }^{28}$ Cfr. KRIPPENDORFF, Klaus, Metodología de Análisis de Contenido. Teoría y Práctica, Paidós, Barcelona,1990, p.28.

${ }^{29}$ Cfr. SCHÜTZ, A. Fenomenología del Mundo Social, Paidós, Buenos Aires, 1972.

${ }^{30}$ Cfr. BERGER, P., y LUCKMANN, T. The Social Construction of Reality: A Treatise in the Sociology of Knowledge, Penguin. Londres, 1966.

${ }^{31}$ El Baròmetre de la Comunicació i la Cultura es el estudio de audiencia más completo de los que se realizan en Cataluña. Se analizan 1.500 medios de comunicación y se entrevistan 40.000 personas anualmente. Los datos se hacen públicos cuatro veces cada año.

${ }^{32}$ La selección de las noticias sobre jóvenes se ha basado en los siguientes criterios: cuando la edad de uno de los actores se explicite y sea entre 15 y 29 años (franja que fija la Secretaría de Juventud de la Generalitat de Cataluña), cuando por la imagen se pueda deducir que es joven, cuando se hable directamente de personas jóvenes (explícita o implícita), o cuando, a pesar de no hablar directamente de personas jóvenes, usen sinónimos: adolescente, chico/a u otras categorías específicas (estudiante,...).

${ }^{33}$ Tanto en las entrevistas en profundidad como en el grupo de discusión se tuvo en consideración la edad de los participantes. Se consideró que no se puede hablar de jóvenes sin darles voz y por eso la mitad de los participantes se seleccionó en función de su edad menor de 29 años. 